\title{
EL RECURSO DEL MÉTODO DE ALEJO CARPENTIER. CRÓNICA DE UNA REBELIÓN ANUNCIADA
}

\section{Alejo Carpentier: cronista de una particular historia}

Tenemos a un hombre cuyo ofício no sólo es serlo: es novelista. Tenemos a un novelista que no es como cualquier novelista: es un cronista. Tenemos a un cronista que no escribe cualquier crónica. Su crónica es la crónica de América Latina. Su nacionalidad, cubana; su nombre, Alejo Carpentier.

Claro que este gran cronista no hace mero testimonio de la realidad latinoamericana del siglo $\mathrm{XX}$, siglo reflejo de realidades anteriores, que conviven o se superponen, se prolongan o se renuevan en esa, esta actualidad que pronto dejará de serlo para hacerse un nuevo presente, pero conocido, familiar; familiar pero diferente, al menos para quien, como Alejo Carpentier, se empeña en esto último. No es mero testimonio, no; no es transmisión de ideas, sentimientos, interpretaciones de un hecho, de muchos hechos, de infinitud de hechos sobre los que dirige su mirada la Historia, que es la historia de los hombres todos, que es la historia hecha por este hombre, y por el otro, y por el de más allá, y por el de aquél, y por el de aquélla y, cada uno, con su particular mirada, haciendo, bien las veces de espejo deforme y cóncavo, bien las veces de espejo llano y uniforme. No se puede decir que haya interpretación alguna en el hacer de este novelista, no. Y no, por lo dicho anteriormente, porque se trata de una crónica que, como película o foto, Alejo Carpentier ofrece al mundo. Película o foto que no tiene director que la dirija o fotógrafo que la revele haciéndolas pasar por el simple artificio de la creación que quiere serlo o sólo quiere ser eso. Por supuesto, su ofrecimiento está hecho de la materia novelada y, a ésta, sólo puede darle forma un profesional de la imagen, de la idea y de la palabra, en el más amplio sentido de lo que cada uno de estos tres ingredientes implica; pero la pluma, el bolígrafo o el lápiz no los sostiene sóio el escritor que es Carpentier; quien realmente los sostiene es la Historia misma. Es la Historia y sólo la Historia la que aprieta sus dedos soltando esa tinta negra, gris o azul con que la realidad se dibuja a si misma. $Y$ es realidad de una verdaderamente maravillosa porción de la tierra en la que, como testigo activo y escritor de acción, participó el novelista cubano en este ya casi pasado siglo XX. Y esto es así porque antes que escritor se consideraba ciudadano, cuyo destino mejor, tomando las palabras de Montaigne, es " el de desempeñar cabalmente su oficio de Hombre" 1 . Tal oficio, nos dice, trató de ponerlo en práctica dentro de una revolución (la cubana) y, como sin pueblo no hay ésta, no pudo, no quiso trabajar en soledad y, por tanto, y ante los acontecimientos que su presente (no muy diferente del de hoy) estaba soportando, afirmaba rotundamente "el comienzo de los tiempos de la solidaridad" 2 . Esta es la idea que se mantiene como motor creador de sus ensayos, cuentos y novelas. Idea constante, siempre presente en su memoria, centro inviolable al que se dirigen sus pensamientos, espa- 
cio hecho de la pasta de esa historia que hace suya en tanto que es real y, por serlo, lo es también de todos, hasta de los de aquellos que no quieren comprender ni intervenir.

\section{América despierta sobresaltada}

\section{Renacimiento latinoamericano}

El motivo que genera esta exposición es el de intentar participar en el análisis y comprensión de una de las novelas del escritor cubano que, por lo demás, no es sino un viaje más por el ancho y clarificador mundo de su pensamiento; un viaje que el lector hace por la historia -ni mucho menos lejana- de Latinoamérica y cuyo punto de partida se sitúa en los momentos previos a la Primera Guerra Mundial, es decir, poco antes de 1914, y que continúa hasta los comienzos del gobierno de Mussolini en Italia, hacia 1924. La novela se titula $E l$ recurso del método. Pero antes de continuar, cabria hacerse la pregunta de por qué Alejo Carpentier nos ubica su narración, en un primer momento, en esta primera Gran Guerra. Vale la pena detenerse en lo que él mismo nos dice al respecto:

hasta la guerra de 1914-1918 los acontecimientos de la política y la historia de Europa tienen muy poca, por no decir ninguna, repercusión en nuestros paises de América Latina. La guerra del 70, franco-prusiana con la constitución de Alemania en Imperio, con la comuna y todos los acontecimientos que la siguieron, no tuvo repercusión en América (...). La historia del siglo XIX tiene muy poca influencia en nosotros. Sin embargo, la guerra del 14-18 ( y por eso me dicen algunos: "¿Por qué tú haces intervenir la guerra del 14-18 en tu novela $E l$ recurso del método y no la última que fue muchisimo más cruenta?". Pero es que la última la esperábamos, la última sabíamos que iba a llegar tarde o temprano), no solamente nos tomó desprevenidos después de cincuenta años en que no habia habido una guerra en Europa, sino que tuvo una influencia decisiva sobre nuestra economía, provocando fortunas, encumbramientos, ruinas de toda índole (...). Y desde la guerra del 14-18 nos hemos dado cuenta de que ya no podemos quedarnos al margen de la historia universal, porque aunque queramos ignorar lo que ocurre lejos de nuestras costas, del otro lado del océano, nada de lo que ocurre en el mundo noses ajeno y hemos de sufrir, para bien o para mal, las consecuencias de cuanto nos rodea3.

Se comprende, por sus palabras, que la repercusión mundial que originó esta guerra, alcanzó limites insospechados hasta el momento en América Latina, limites no sólo políticos o históricos, sino también económicos e ideológicos que hasta entonces apenas podían ser intuidos por sólo unos pocos. Esta es la razón por la que Alejo Carpentier concede máxima importancia a este momento histórico que él presenció cuando era niño y que comprendió posteriormente (como comprendieron muchos de su generación) hasta dónde podían llegar las consecuencias pues, para él, como para muchos jóvenes con quienes se habría de unir física o ideológicamente andando el tiempo, "no fue sino el comienzo de una gran guerra que prosigue hasta nuestros días"4.

Pero volviendo a los resultados inmediatos que generó la guerra, hay que tener en cuenta otra de las afirmaciones que hizo el escritor y que tiene que ver con la década en la que la 
acción de El recurso del método se sitúa, es decir, para él, el periodo de 1914-1924 es, a su juicio, “jel más importante que en este siglo haya vivido en lo artístico, literario e ideológico América Latina!" 5 . Lo que con esto quiere expresar es que, dentro del terreno cultural, empiezan a verse diferentes rumbos que auguran una América nueva; una América que empieza a interesarse por lo que está pasando en Europa, por esa paz que no llegaba con el armisticio del 11 de noviembre de 1918, porque ya en octubre de 1917 estaba sucediendo otra suerte de acontecimientos importantes, como fueron los que se refieren a la Revolución Soviética, cuya significación resultó ser enorme en todo el mundo, a partir de la instauración de un sistema socialista que arrancaba de las bases teóricas del marxismo-leninismo.

\section{Madurez ideológica de una generación}

Muchos jóvenes latinoamericanos se estaban formando entonces dentro del modernismo, dentro del esteticismo, creando mundos ficticios y estériles, ajenos a lo que se estaba fraguando en Europa. Pero hacia 1923-1924 comienza la carrera cuesta arriba de una juventud que empieza a preocuparse por lo que estaba ocurriendo no sólo dentro del ámbito caribeño al que pertenece Carpentier, sino también fuera, al otro lado del océano. Surge así el llamado Grupo Minorista, del que fue miembro el escritor cubano, y en el que se compartían ideas afines entorno a lo que tanto intelectual como políticamente estaba sucediendo en el mundo. En este sentido cuenta Alejo:

Hablábamos mucho de Picasso, de Stravinsky, de los poetas nuevos. Pero también hablábamos mucho de la Revolución de Octubre y de "los diez dias que conmovieron al mundo". Pronto, numerosos miembros del grupo, se proclamaron comunistas, aunque sin entregarse a una militancia real, ignorantes, a veces, de los textos fundamentales. Pero habia una verdad generalmente admitida: si una transformación de la vida artística e intelectual del mundo se había hecho necesaria, también se hacía necesaria una transformación de la sociedad ${ }^{6}$.

El compromiso político y cultural de este grupo concentra toda sus energías en la idea de revolución, nombrándose a sí mismo como generación marxista. En el aspecto cultural, pretenden establecer un vínculo efectivo entre revolución y literatura, haciendo de ésta un medio con que reivindicar la teoria y la practica revolucionarias. Es de este vínculo de donde se desprende la concepción carpenteriana de la novela y del novelista latinoamericano contemporáneos y que se verá más adelante. En lo que se refiere a la cuestión política propiamente dicha, la acción del Grupo Minorista se revela como fuerza que milita "contra las dictaduras políticas unipersonales en el mundo, en América, en Cuba. Por la cordialidad y la unión latinoamericana"7, utilizando las propias palabras del escritor.

\section{La inyección francesa}

Antes de llegar a este punto, punto de partida para poder adentrarse en el estudio de la novela que nos ocupa, conviene hacer referencia a la situación en que Latinoamérica se encontraba con respecto a Europa y el interés por lo francés que se venia ejerciendo desde el pasado siglo. En una entrevista que se le hizo al novelista en Paris, en 1976, decía que la razón por la que los intelectuales latinoamericanos ponían sus ojos en lo que, dentro del orden 
cultural, se venía gestando en Francia, -y que tenia que ver con las ideas que tras la Revolución francesa promovieron las luchas por la independencia en América Latina-, no fue por otra cosa que por la precariedad cultural que, en términos generales, presentaba España entonces ("es un hecho cierto que el siglo XIX español fue, intelectualmente hablando, uno de los siglos más pobres de la cultura europea" ${ }^{8}$ ). Alejo Carpentier explicaba también cómo ese interés por lo francés, por su literatura, por su pintura, por su música, por la gran producción artística que el país estaba ofreciendo, vino de la mano, en un primer momento, de lo que llama " una nueva clase, una nueva casta, una nueva raza" 9 , es decir, la de los criollos, cuyo término alcanza una significación crucial para él, pero que no es objeto de tratamiento por el momento. Esta nueva casta, dice, se emborracharia de cultura francesa hasta alcanzar el siglo XX, llegando a salpicar incluso a cierta clase de dictadores como Porfirio Díaz en México o Guzmán Blanco en Venezuela.

Y vamos, poco a poco, aproximándonos más a la burbuja espesa que envuelve el mundo del protagonista de El recurso del método, que no es otro que el de un tirano ilustrado, afrancesado.

El retablo político del titiritero del norte

Pero, ¿qué ocurre después? Ocurre que el lobo siempre duerme con las orejas en alto, los ojos abiertos y las uñas bien afiladas. Se puede parar uno a reflexionar sobre lo que dice el escritor, pues, con ello, no hacemos más que abrir la novela carpenteriana por el lado mismo de su corazón:

Es entonces cuando, con una campaña hábilmente orquestada, decididos a penetrar solapadamente en América Latina, no sólo a adquirir sus industrias, sus riquezas, sino también a convertirse en maestros de su cultura, Estados Unidos comienza a decirnos: "Pero, ¿por qué miran ustedes hacia Francia?. Europa está en decadencia, la vieja Europa está acabada, ya no queda nada que buscar por ese lado; nosotros somos los maestros de la técnica, somos nosotros los que vamos a ayudarlos". Y a partir de ello Estados Unidos se impone en nuestra cultura, transformando nuestros hábitos, transformando nuestras costumbres, en cierto sentido, a través de la publicidad, de los periódicos, y de todo su aparato; y esto conduce, al fin y al cabo, a la dictadura de un Pinochet, de un Banzer en Bolivia, al mantenimiento durante más de veinte años de un Stroessner, en Paraguay, que son actualmente los protectores de los últimos jefes nazis, que son los protectores de los que han construido los hornos crematorios y que se han hecho cómplices del peor fascismo en Europa ${ }^{10}$.

Y es ahora precisamente cuando podemos atender a las razones que llevaron a Carpentier a escribir su novela, El recurso del método, publicada en 1974, y cuya acción, como ya se ha dicho, se desarrolla hacia 1913, cuando el fervor por lo francés, manifestado expresamente por las clases dominantes, no disminuyó ni mucho menos hasta el punto de desaparecer, pero empezó a ser sustituido por la atracción hipnotizadora de la cultura norteamericana. Los colmillos babeantes del imperialismo yanqui empezaban a asomarse sobre una América que no tardaría en mostrar su verdadero rostro. 


\section{El títere mayor}

Carpentier, como ciudadano que no puede ignorar su realidad, realidad que es consecuencia de un pasado, de una historia de días, meses, años y siglos como eslabones fuertemente aferrados uno al otro, sin posibilidad de que uno sólo pueda extraviarse en el tiempo, es consciente del padecimiento que las gentes del continente americano han venido sufriendo tras finalizar las guerras de la independencia. La irrupción que en la escena del territorio hizo el dictador latinoamericano no vino más que a subyugar la voluntad de un pueblo que apenas comenzaba a respirar. Sólo la primera batalla parecía estar perdida y el siglo XX no había hecho más que empezar. Es por eso por lo que el cubano nos presenta desde las primeras páginas de su novela al dictador, a quien llama Primer Magistrado, despertándose de un ligero sueño, poco reparador: "pero si acabo de acostarme. Y ya suena el timbre" 11 , gruñe contrariado. En efecto, la novela así se abre y, quizá, ya se nos esté sugiriendo, casi sin darnos cuenta, qué está pasando: este hombre no descansa, ¿las horas transcurren a tal velocidad que el sonido del despertador no puede más que sorprenderle?, ¿descansa pero no duerme?, ¿quién retorna a la vigilia y por qué?, ¿ porque el timbre, el tiempo juega en su contra?, ¿quién o qué no le deja descansar?, ¿quién despierta a quién?. Pudieran ser vanas, aventuradas o inmotivadas preguntas, sí. Pero vayamos poco a poco.

El manifiesto firmado por el Grupo Minorista en 1927 contra el imperialismo y las dictaduras, llevó a Alejo Carpentier a la cárcel. Cuba, por entonces, se encontraba bajo el régimen de Gerardo Machado, tirano que se mantuvo en el poder desde 1925 hasta 1933 y al que llamaban, ni más ni menos, el "Mussolini tropical". Siete fueron los meses que estuvo preso y, como él mismo recuerda, probablemente ahí fue donde "surgió la primera idea de la novela" 12 .

\section{Alejo Carpentier: espectador de la Historia}

Son múltiples los elementos con los que juega el escritor en esta gran novela, los cuales se dejan ver tanto en los diálogos, como en las descripciones, como también en los enfoques adoptados. En El recurso del método, como en sus mayores narraciones, se advierten ciertas constantes que no vienen a ser sino la constatación de sus propias concepciones literarias y políticas, expresadas en conferencias, ensayos o entrevistas. Su idea de Latinoamérica y del papel que el novelista desempeña en este contexto no se pueden ignorar si queremos entender sus novelas, desde El reino de este mundo (1943), hasta la última, El arpa y la sombra (1979). En todas ellas, -sin olvidar la primera, Ecue-Yamba-Ó (1933) que, aunque forma parte de la corriente indigenista, no está ausente la inquietud politica y social-, se mantiene siempre presente la preocupación por mostrar "la existencia del hombre americano"13. Preocupación a la que Alejo Carpentier no ha podido llegar sin antes descubrir las respuestas que la Historia le proporciona, sin antes vacunarse contra la ignorancia, la indiferencia o, acaso, el olvido.

El hombre, como cualquier hombre, es un ser hecho de historia y la historia del hombre americano es aquella que se enclava en unas circunstancias particulares que le llevaron a ser lo que es hoy, testigo consciente y victima del hombre de poder, de la violencia y la fuerza, de la explotación, la opresión, el control omnímodo de las clases dirigentes, a su vez directoras 
del pensamiento de otros hombres que, traicionando sus origenes o sus principios, traicionaron también a su propio pueblo. Eso ha sido y sigue siendo América Latina; pero las conciencias libres, cuyo poder sólo se encuentra en el conocimiento y la causa del ser americano, en una suerte de inmunidad aprendida tras largo tiempo de sufrimiento, han venido a dar la vuelta a esa moneda y, con ello, a iniciar un proceso ascendente de resistencia contra toda forma posible de tiranía. El peso de la balanza ha cedido de un lado y ha cedido del otro; parece que ha estado cediendo más de uno, durante demasiados años. No obstante, ese otro platillo nunca se ha permitido tocar suelo, tocar fondo; existe una fuerza brutal que sólo acaba de comenzar a reducir a la fuerza tradicional y milenaria: se llama revolución.

\section{EI recurso del método: novela del dictador latinoamericano}

\section{La inquietud viene de muy atrás}

En cierta reseña referida al texto, Rita Gnutzmann señala que se trata de una "novela en que se propone hacer un análisis del prototipo del dictador y de la dictadura hispanoamericana"14. Bien, pero, ¿de dónde arranca esta temática, que como afirma Víctor Bravo, "también es punto de partida válido para la indagación novelística sobre la soledad y el poder" ${ }^{5}$ ?. En una entrevista realizada por Edgar Montiel en Lima, en 1975, el escritor explica que este interés por presentar al dictador hispanoamericano se produce por una necesidad histórica ${ }^{16}$, cuyos antecedentes temáticos se pueden encontrar en Tirano Banderas (1926), de Ramón del Valle-Inclán, El Señor Presidente (1948), de Miguel Ángel Asturias, o Yo, El Supremo (1974), de Augusto Roa Bastos. Se encontraría escrita posteriormente la novela de Gabriel García Márquez, El otoño del patriarca, de 1975. No obstante, Alejo Carpentier se remonta mucho más atrás para hablarnos del escritor iniciador de este motivo:

Yo diría que en la literatura que se refiere en América Latina al personaje del dictador el precursor fue Esteban Echevarria, el escritor argentino nacido en 1805, muerto en 1851... Esteban Echevarría dio la norma y marcó el punto de partida de una literatura en que se muestra al dictador latinoamericano tal y como es. Debo confesar que su relato El matadero, que admiro profundamente -porque el escritor juega alli de una manera maravillosa con la naturaleza, con el aspecto geográfico y étnico de una ciudad sometida a la dictadura de Rosas- me impresionó tanto, que en el capitulo de mi novela que pinta el asalto a Nueva Córdoba por las tropas del gobierno, el pequeño episodio que ocurre en el matadero de la ciudades un homenaje que rindo voluntariamente a quien considero como un clásico de este tipo de narrativa ${ }^{17}$.

Pero, ¿cómo es realmente el dictador latinoamericano del que nos habla Carpentier?. En El recurso del método se nos presenta la figura arquetípica de un tirano que representa a todos o a muchos de los que forzaron al pueblo a vivir bajo las consignas del terror y la violencia. Un tirano que se asienta en el poder y hace todo lo que esté en sus sucias manos para mantenerse en él. Una larga serie de corrupciones, traiciones, masacres, engaños, robos y represiones practicadas en un pequeño país sin nombre, que no lo tiene porque representa ni más ni menos que a todo el Continente. 


\section{Padrinos de vampiros}

La realidad política y social de América Latina ha girado entorno a los recursos de poder desde el Descubrimiento. En la novela, Alejo Carpentier deja ver el resultado de ello: la dependencia, no sólo económica o comercial, sino también vital o estructural ${ }^{18}$ de las potencias capitalistas. El poder ejercido por el Primer Magistrado se sostiene en tanto que depende de ellas; es un poder sobre la cuerda floja:

Cable a Ariel, su hijo, embajador de Washington, disponiéndose la inmediata compra de armamentos, parque, material logístico y globos de observación como los que recientemente habia adoptado el Ejército Francés (...), procediéndose,-para ello, puesto que toda guerra es cara y el Tesoro Nacional andaba muy maltrecho, a la cesión, a la United Fruit Co., de la zona bananera del Pacífico - operación demorada desde hacía demasiado tiempo, por los peros, alegatos y objeciones, de catedráticos e intelectuales que no sabian sino hablar de pendejadas, denunciando las apetencias (...) del imperialismo yanqui ${ }^{19}$.

Incluso a pesar de la prosperidad económica propiciada por la guerra europea y "bendición de Dios" ${ }^{20}$ para el Primer Magistrado ("el azúcar, el banano, el café, el balatá, alcanzaban cotizaciones nunca vistas, hinchando las cuentas bancarias, levantando fortunas, trayendo lujos y refinamientos"2l), el desarrollo social, la introducción de la cultura, la transformación rápida de la ciudad y la asimilación de nuevas modas, no garantizan la desaparición de ciertas costumbres anacrónicas, necesarias, por lo demás, para el mantenimiento del "orden" y la "paz social" que, al fin y al cabo, podían peligrar a raiz de este caos mundial. Un ejemplo, quizá el más significativo, de los contrastes de esta realidad latinoamericana, es el subdesarrollo de un pueblo auspiciado por el desarrollo económico de las clases dominantes (o con posibilidad de serlo), que se perpetúan en el poder y se sustentan gracias a la existencia de los más débiles. A pesar de las transformaciones sociales y culturales, las viejas conciencias no cambian; la macabra bendición de la guerra persigue, en definitiva, el perpetuo amén del subdesarrollo.

José Alcántara Almánzar, en un estudio dedicado a la novela ${ }^{22}$, habla de este estado de cosas: ahí está la realidad del "mestizaje":

Varias tetas había tenido la Loba de Rómulo y Remo (...) para cuanto cholo o zamba se colgara de ellas. Decir Latitinidad era decir mestizaje, y todos éramos mestizos en América Latina ${ }^{23}$,

"la discriminación":

Sin darse cuenta de ello, las gentes vivían en Ninives insospechadas, en Westminsteres vertiginosos, en Trianones volantes, con gárgolas y personajes de bronce, que llegarian a viejos sin haberse tratado con la gente de abajo, atareada ésta entre pórticos, arcadas, soportales, que cargaban con un enorme peso de construcciones inalcanzables para la vista $^{24}$,

"la ridícula persecución contra la literatura roja, entre comillas",

A las tres, ocuparon las autoridades (...) distintas librerias que ofrecian al público, en ediciones económicas, libros tales como La semana roja de Barcelona (...), El caballero 
de la Casa Roja, El lirio rojo, La aurora roja (Pío Baroja), La virgen roja (biografia de Louise Michel), El rojo y el negro, La letra roja de Nathaniel Hawthorne - exponentes todos, (...), de una literatura roja, de propaganda revolucionaria ${ }^{25}$

"la hipertrofia de los ejércitos y el procedimiento paternalista en el reclutamiento de soldados, tan caro a la dictadura":

El movimiento se habia extendido a tres provincias del Norte, amenazando la banda del Pacifico. Pero las guarniciones y la oficialidad del Centro, seguian fieles al Gobierno... La moral de las tropas gubernamentales era buena, pero el armamento resultaba insuficiente... Se esperaban instrucciones. —“ Coño de madre! ¡Hijo de puta”repetía el Primer Magistrado, como si a estas únicas palabras se hubiese limitado su vocabulario, al pensar en la felonía de quien había sacado de la mugre de un cuartel de segunda, amparándolo, enriqueciéndolo, enseñándole a usar un tenedor, a halar la cadena del retrete, haciéndolo gente, dándole galones y charretera, nombrándolo finalmente Ministro de Guerra ${ }^{26}$.

\section{La América de hoy nació en un campo de batalla}

Tales hechos que se mencionan en la novela se corresponden con el tiempo de la acción en que ésta se sitúa. Ya se ha hablado de por qué Alejo Carpentier eligió el período que va desde poco antes de iniciarse la Primera Guerra Mundial hasta los comienzos del gobierno de Mussolini en Italia, en 1924. Cabe decir, no obstante, que sus novelas no solamente se asientan sobre una base histórica fidedigna, sino que los motivos representados no se encuentran demasiado lejos de la actualidad.

La realidad histórica de Latinoamérica, expuesta en El recurso del método, no ha cambiado demasiado andando el tiempo. El capitalismo, tal y como hoy lo conocemos, iniciado a finales del siglo XIX, es objeto de crítica constante por parte del escritor cubano. El imperialismo, el norteamericano en particular y, con él, la ocupación a la que se vieron sometidos los paises del Sur, son criticados con clara contundencia "siempre por medio de alusiones de gran ironía o expresiones puestas en boca del Primer Magistrado y sus allegados"27:

... Varios marines - polainas blancas, camisas resudadas, ojos de bastante ron- están apostados en todos los andenes. Me entero de que ya ocupan la planta eléctrica, los centros vitales, bares y burdeles de la ciudad, después de haberse meado, de paso, sobre el Monumento a los Héroes de la Independencia ${ }^{28}$.

El poder europeo ha cedido paso al poder norteamericano y, a base de poder y de luchas contra él, se vino a formar la historia moderna de América Latina:

En el siglo XX los países de nuestra América, dotados de una fuerte conciencia nacional, lucharon y luchan contra el imperialismo, aliado de una gran burguesia criolla, por el logro de una independencia total, unida a un anhelo de progreso social. $Y$ esta segunda parte del siglo XX se ha caracterizado y se caracterizará por la intensificación de esa lucha en todo ese ámbito del Caribe, lucha por una independencia total, independencia total ya lograda en $\mathrm{Cuba}^{29}$.

Visto a grandes rasgos el panorama social, político y literario de una Latinoamérica, la única, producto de influencias, dependencias e intereses extranjeros, mas no por ello quedan- 
do menguada su propia idiosincrasia, se puede decir, al fin, que El recurso del método no es sino el compendio y análisis que hace Alejo Carpentier del "sub-mundo" vivido en el territorio por la dictadura y sus consecuencias durante prácticamente todo el siglo $\mathrm{XX}$, pues aun teniendo en cuenta que el reinado del Mandatario dura alrededor de catorce años, -no por otra cosa que por la alusión a determinados hechos históricos producidos entre 1913 y 1927-, el escritor parece tener bien presente la continuidad del viejo método al concluir su novela con un epílogo precedido de una fecha, 1972, y en el cual nos muestra la imagen del Cementerio de Montparnasse, en París, donde leemos que el ex-dictador, tras una larga agonía, había tomado sepultura.

\section{El hoy de la novela y el novelista latinoamericanos}

\section{Yo soy yo y la realidad}

Ya se hizo referencia anteriormente a los antecedentes literarios que el texto tiene como novela del dictador. Pero advirtamos ahora el ingrediente original que separa ésta de aquellos. Para ello, no podemos pasar por alto, si queremos llegar a este punto, la concepción que el escritor cubano tiene acerca de la novela y su ejercicio como novelista. No se podría comprender de otro modo. Empecemos por decir que toda o casi toda su producción es llevada a cabo partiendo de una idea principal e incontrovertible: con la picaresca española se inaugura la novela moderna. Dicha picaresca, esto es lo importante, conlleva el empleo, no usado hasta entonces, de una primera persona, el "yo", sumergido en el contexto de la realidad:

Con la picaresca española (...) nace realmente la novela como hoy la entendemos. Novela con su novelística. Novela que es invención totalmente española, sin antecedentes extranjeros, y que, por su novedad, por su poder de calar en lo hondo de lo circundante, será pronto traducida a varios idiomas, hallando un sinnúmero de imitadores en Francia y en Inglaterra ${ }^{30}$.

Para Carpentier, este "primer movimiento novelístico universal" 31 , fue enteramente revolucionario dentro de la historia de la literatura, pues representa una "comedia humana total y completa" 32 de una realidad que, pudiendo parecer cómica a los ojos del lector, resulta ser cotidiana o habitual.

\section{Yo soy yo y mis sueños}

Sin embargo, este genial cubano va mucho más allá al reconocer que, si bien los orígenes de esa picaresca se encuentran en El Lazarillo de Tormes, en El buscón de Quevedo o en la Vida del escudero Marcos de Obregón, de Vicente Espinel, no se había llegado a alcanzar esa eterna dimensión que aparecería con El Quijote de Cervantes. Ese "yo" que hablaba por boca de los primeros pícaros no le basta a nuestro escritor, pues se vuelve hueco y simple monigote de divertimento. El lector no puede identificarse con él y le observa con cierto distanciamiento:

Pero ese yo forma parte de lo circundante y habitual. Nada añade, sustancialmente, a una realidad muy española, donde los Pablos de Segovia, los Marcos de Obregón, los 
Estebanillos González, carecían del espesor, de la densidad, la ejemplaridad suficientes para encarnar el genio de una raza. Un pueblo puede divertirse largamente con los antihéroes, pero no se reconoce en ellos ${ }^{33}$.

En efecto, el elemento que estaba aguardando la novela moderna para alcanzar su más completa perfección, no llegaría sino bajo las órdenes de la pluma cervantina:

Faltaba a la picaresca, pese a la importancia capital de su aportación, esa cuarta dimensión del hombre que es la dimensión imaginaria. Y esa era la dimensión que Cervantes nos habia traido con su Quijote, novela que pasa por la mejor picaresca sin inscribirse en ella...

Cervantes, con el Quijote, instala la dimensión imaginaria dentro del hombre, con todas sus implicaciones terribles o magníficas, destructoras o poéticas, novedosas o inventivas, haciendo de ese nuevo yo medio de indagación y conocimiento del hombre ${ }^{34}$.

La penetración inevitable de la cuarta dimensión

Y es ésta la gran innovación, la quizá insuperable innovación que, como muchos otros, Alejo Carpentier descubrió en la obra inmortal. La realidad ya estaba dada, la podíamos encontrar a cada paso, en cada momento del día, siempre ahí, constante: el yo se encontraba frente al tú como si no fuera suyo, pero al que podía tocar como si lo fuera y, sobre todo, sentir. ¿Y cómo fundir esa dimensión imaginaria de la que el hombre está hecho?, ¿cómo entretejer los hilos de su ser imaginado?, ¿cómo penetrar su dimensión irreal en ese plano aparentemente impenetrable de la realidad y, además "sin que se vean las costuras" ${ }^{35}$ ?. Eso lo supo hacer por primera vez en una novela la mano maestra de don Miguel de Cervantes Saavedra. $\mathrm{Y}$ es desde entonces, afirma Carpentier, que "todo está permitido al ente creador" 36 .

\section{Un pícaro descomunal}

Esta libertad del escritor que adopta el autor de El recurso del método se va a observar desde el comienzo de la novela, pero atendiendo a un punto de mira particular. Si bien los pícaros españoles se nos mostraban como los antihéroes objeto de risa, inmersos en una realidad, la española, en la que se limitaban a sobrevivir a base de trampas y engaños sin llegar, como dice el cubano, a matar a nadie, el pícaro que resulta ser el Primer Magistrado, se nos vuelve ejemplo máximo de crueldad, violencia (“fuego!, era la regla del juego”37) y corrupción ("y voces misteriosas...empezaron a cuchichear...que cualquier voto sería conocido por las autoridades campesinas o municipales" 38 ). Hombre este para quien los únicos medios de salvación se reducen al plomo o a la soga contra aquellos que participan de una realidad que se le resiste y le incomoda. No se trata sino del pícaro que en Latinoamérica cobró dimensiones espectaculares e inverosimiles, pero trágicamente reales. Es el pícaro que, en su largo viaje desde tierras españolas, tuvo tiempo de crecerse junto con el inmenso océano que le transportaba, dotándole de un poder inconmensurable que el empuje de las olas le fue proporcionando al tiempo que se aproximaba a tierra. Y es que Alejo incorpora a su campo de visión la imagen del pícaro Pablos que, al final de la novela de Quevedo, se embarca rumbo a América, para decirnos que Lizardi, con su Periquillo Sarniento, publicado en 1830, toma 
el relevo de la última novela picaresca que vendria a inscribirse como "la primera gran novela latinoamericana":

...me di cuenta un buen día que ese pícaro español, ocurrente, tramposo, fullero, mentiroso, grato en algunos momentos, ingenioso siempre, al pasar a América (...) se nos agigantaba en un continente agigantado.

En un continente inmenso, con ríos inmensos, con montañas inmensas, con inmensas tierras, el pícaro cobraba apetencias nuevas y dejaba de ser personajillo medio culto y gracioso, para transformarse primero en el político anunciador del politiquero. Después en el presidente de las elecciones amañadas, después en el general de los cuartelazos y, finalmente, civil o general, en el dictador. Es decir, el pícaro español pasaba, de un plano secundario, a un plano histórico para desgracia nuestra, puesto que en el continente donde vivimos nos encontramos que la galería de dictadores es una cosa tan monstruosa que desconcierta al entendimiento más razonable ${ }^{39}$.

\section{Tarea del novelista actual}

\section{- El lugar que ocupa el escritor}

Es precisamente ese análisis de la historia latinoamericana, teñida de sangre derramada por manos del nuevo pícaro, el que nos lleva a comprender los motivos del escritor cubano. Motivos que no surgen sino de su más cabal conciencia histórica y le llevan a recrear a un personaje concebido como arquetipo representante de un gran número de tiranos instalados en el Continente (Gerardo Machado, Guzmán Blanco, Cipriano Castro, Estrada Cabrera; Tujillo, Porfirio Diaz) e incluso fuera de él (Franco, Mussolini). Motivos que le llevan, además, a dar forma a esa "contra-fuerza" reductora de la opresión llamada en la novela El Estudiante, director de una gran masa que es el pueblo y al que viene a levantar del polvo de esa tierra mancillada por años, siglos de exterminio, ejecuciones y masacres. Motivos, en fin, que conducen a Carpentier a colocarse en la primera fila de espectadores y actuar:

Ocuparse de ese mundo, de ese pequeño mundo, de ese grandisimo mundo, es la tarea del novelista actual. Entenderse con él, con ese pueblo combatiente, criticarlo, exaltarlo, pintarlo, amarlo, tratar de comprenderlo, tratar de hablarle, de hablar de él, de mostrarlo, de mostrar en él las entretelas, los errores, las grandezas y las miserias: de hablar de él más y más, a quienes permanezcan sentados al borde del camino, inertes, esperando no sé qué, o quizás nada, pero que tienen, sin embargo, necesidad de que se les diga algo para removerlos ${ }^{40}$.

Y esta actuación es lo que le permite al escritor conocer todo cuanto le rodea, indagando en los pormenores y en los acontecimientos extraordinarios, profundizando, investigando el ser y la razón de ser de los hechos. Hechos estos que, desde los comienzos de la centuria, han entrado a formar parte de la era del cambio, como apunta Alejo Carpentier. Ya no es momento de transcribir los procesos mentales de tipos individuales que se encierran en sus propias experiencias. Ahora es momento de retratar el contexto social, colectivo, en el que los grupos de hombres se debaten con sus contingencias históricas, grabando la huella de sus pasos en el denso e incandescente magma del tiempo. 


\section{- El combate del hombre nuevo: la nueva épica}

El escritor considera que "no hay mundo semejante al latinoamericano en cuanto al hecho de que el hombre está trabado en lucha contra los elementos, en lucha contra la naturaleza, en lucha con el ámbito político, en lucha con todo lo que lo circunda, lo rodea, lo encierra, lo limita o le da posibilidad de expansión" ${ }^{1}$. Esta lucha del hombre con el hombre, unas veces contra y otras veces por el hombre, es algo que existe, que está ahí y a lo que no se puede ser indiferente; $y$, por ello, le corresponde al creador introducir la "dimensión épica" dentro de la novela latinoamericana. Por señalar algunas de sus mejores narraciones, la lucha contra la esclavitud en El reino de este mundo (1949), alcanza esa dimensión épica; la alcanza también el proceso de desenajenación, aunque infructuoso, que quiere experimentar el narrador protagonista al verse sometido a la hipnosis ejercida por la moderna sociedad capitalista, en Los pasos perdidos (1953); novela épica es también la que lleva a la práctica "la revolución como agente transformador" en El siglo de las luces (1962), donde la frase puesta en boca de Sofía "ihay que hacer algo!42", legitima el hecho épico como realidad incuestionable; y dimensión épica es la que cobra el escenario donde se suceden los hechos en La consagración de la primavera (1978), desde la Revolución bolchevique hasta la Revolución cubana, pasando por la Guerra civil española y la ascensión del nazismo en Europa, constituyendo todo ello "un canto épico a la voluntad dinámica de los hombres que, sin contentarse con sufrir la historia, pretenden modificarla con la revolución" 43 .

Finalmente, El recurso del método, publicada cuatro años antes que la anterior, se enmarca en un mismo contexto épico en el que el Estudiante encarna "la lucha colectiva" a la que "da razón y organización, proyectos y metas", que actúa como "movimiento subversivo y revolucionario" cuyo primer objetivo es "derrocar al tirano", avanzando "en directa relación con la apropiación que hace el Imperio de la economía y de la vida cotidiana del país" ${ }^{44}$.

\section{- Razones del ser americano: contexto total en El recurso del método}

Esta perspectiva que toma Alejo Carpentier para abordar la historia y, con ello, describirla, le lleva a cumplir una función revolucionaria. En todas sus novelas, este objetivo le predispone a investigar la realidad latinoamericana que, como el historiador o el sociólogo, analiza, parte por parte, cada uno de los estratos de que se compone dicha realidad. Y porque el hombre se encuentra en íntima unión con ella, no se le puede separar de los contextos que le confieren su particular forma y su particular fondo. Dicho de otro modo, no puede haber dimensión épica si no se muestran o describen los elementos con los que el hombre ha de convivir o contra los que puede luchar y que le proporcionan su más inequívoca esencia. La idea de "contexto", originaria de Jean Paul Sartre, es la que Carpentier retomó y trasladó a sus novelas a partir de la Revolución cubana:

Ahora creo que el novelista latinoamericano ha entrado en lo que podemos llamar dimensión épica; es decir, el novelista latinoamericano puede poner al hombre, a sus personajes, intimamente ligado con sus contextos de naturaleza, dimensión, paisaje, revolución, lucha, o en general, todo lo que compone la vida del hombre ${ }^{45}$. 
En El recurso del método se puede comprobar la puesta en práctica de la reinterpretación que hace el novelista del concepto sartriano dentro del ámbito latinoamericano. En realidad, entre todos esos elementos que integran al hombre existe una relación estrecha puesto que unos son desencadenados por otros o forman parte de ellos. Así, el contexto económico está presente en la dependencia del capital extranjero a que se ve sometido el Primer Magistrado para desplegar todo su poder, cosa que condiciona la vida de un pueblo que debe soportar el despilfarro más absurdo, como el que se lleva a cabo en la construcción de un capitolio nacional, monumento al poder. $\mathrm{O}$ el contexto político, causa y consecuencia del anterior, que en la novela nos viene dado por la instauración de un sistema totalitario constituido a partir de unos comicios nada limpios que permiten su perpetuación, sin olvidar los asaltos al poder por parte de una resistencia adepta también a regímenes represivos o dictatoriales. Unido a esto, se encuentra la lucha ejercida contra cualquiera de estas posibles tiranías, en particular, la de aquella que el Presidente de la República arbitra, y que protagoniza un estudiante en tanto que cerebro de un pueblo que ansia la libertad.

Siguiendo la relación, se puede dar cuenta de un contexto burgués que beneficia a la gran potencia capitalista estadounidense, en la medida en que la ascensión imparable a la que ha llegado su "conejillo" del sur, le permite salvaguardar sus intereses, los cuales se traducen en propiedades adquiridas, monopolios, cesiones como la de la zona bananera del Pacífico a la United Fruit Company, o la no tan simple tarea de sofocar todo posible movimiento anarquizante que pudiera hacer temblar la consecución de objetivos imperialistas.

Ahí están también los contextos de proporción y distancia que genera una realidad natural e indómita, una tierra constituida por volcanes, ciclones, huracanes, terremotos y diluvios, donde la vegetación siempre consigue reconquistar un territorio momentáneamente ocupado por las "vastas urbanizaciones": "ison hierbas que volvían a la Capital con su escolta de campánulas y festivos penachos" 46 ; tierras estas donde "mudaban de curso los ríos abandonando sus cauces de la noche a la mañana"; tierras, en fin, donde librar una batalla se hacía más trabajoso ante la presencia irremediable de las distancias impuestas por "tantas selvas, pantanos y cordilleras" 47 , que obligaban a establecer las comunicaciones "a lomo de mula o de burro (...), cuando no por medio de mensajeros que supieran correr y escurrirse como los chasquis de Atahualpa"48.

Y ¿qué se puede decir del contexto de iluminación sino que hasta para el Primer Magistrado se le vuelve una realidad insobornable y le lleva a decir a su regreso de París: "era aire de mi aire" 49 ?. Contexto de iluminación que en tierras parisinas no le resulta familiar y desorienta a la Mayorala Elmira, puesto que para ella "estas puñeteras calles se ladeaban, se torcían, cambiaban de rumbo, y la sombra -cada vez más pequeña- le pasaba de derecha a izquierda, y no acababa de ponerse en la posición deseada" ${ }^{50}$.

Tampoco puede pasar inadvertido el contexto de desajuste cronológico que emerge de una tradición cultural ya gastada pero sostenida por un dictador que, aunque ilustrado, ignora las nuevas corrientes de una vanguardia que comienza a tomar el relevo. $\mathrm{Y}$ en cuanto al contexto lingüístico, el uso que del lenguaje hace Alejo Carpentier en la novela es enteramente significativo, por la razón de que establece una cadena de contrastes lingüísticos y culturales entre la realidad de allá (Europa, Estados Unidos) y la realidad de acá (América). Así 
podemos ver a la hija del Mandatario, Ofelia, utilizando un léxico "desbocado y guarango que parecía sacado de quilombos, tumbaderas o casas de remolienda”, para terminar regresando a "un idioma fino y sutilmente matizado"51, aprendido en su residencia de París; o cuando el dictador, reunido con su amigo el Ilustre Académico, contamina un lenguaje francés "harto medido, harto cuidado de la pronunciación y la justeza del vocablo", de "improperios criollos" venidos a su memoria ante una situación social que pone en entredicho su autoridad: "Indios, negros, sí; zambos, cholos, pelados, atorrantes, rotos, guajiros, léperos, jijos de la chingada, chusma y morralla"52; o, si no, se trata de un lenguaje que utiliza para establecer contrastes oportunos entre objetos, como el chinchorro querido que siempre acompaña al dictador en sus viajes al París del armatoste que es "la rígida cama de colchón y travesaño", o el recuerdo del volcán "nevado, majestuoso, lejano, antigua Morada de Dioses", que se opone a la realidad física, próxima, del Arco de Triunfo frente a una ventana de su eventual estancia de la casa parisina ${ }^{53}$.

Y se puede ver, además, un contexto culinario que nos trae las esencias, colores y sabores propios latinoamericanos a la casa de la Rue de Tilsit en París. Es la Mayorala Elmira que, sin poder acomodar su paladar a la gastronomía francesa $y$, tras un verdadero carnaval de cocina, muestra, ante los ojos atónitos de Ofelia, "los verdores del guacamole, los rojos del aji, los ocres achocolatados de salsas de donde emergían pechugas y encuentros de pavo, escarchados de cebolla rallada"; consiguiendo, así, que la nariz de la señorita se subyugara a los vapores y aromas de cambures fritos, frituras de batata y barquillas de coco doradas al horno ${ }^{54}$.

No se puede concluir la relación de los contextos sin referirse al que es denominado "ctónico", generado por el mito del Estudiante, unido también, al de Miguel Estatua, otro de los combatientes pero que, a diferencia de aquél, es representante de una rebeldía instintiva y espontánea. Ambos, como apunta el crítico Ariel Dorfman, "aparecen desde el principio, rodeados de un hálito de leyenda, mito, magia, palabras, una re-elaboración colectiva y popular de su existencia, proyectados en hazañas que el pueblo conserva en su memoria y reproduce en su aprendizaje"55. Contexto ctónico que es trasunto de creencias primitivas que conviven con creencias nuevas dentro de una sociedad que renueva su fe en la libertad; mitos que perviven en el tiempo muy a pesar de ese Primer Magistrado, consciente de que "nada camina tanto en este continente" 56 como ellos. $Y$ ahora, con este nuevo hombre, con esta nueva raza que es la que encarna el Estudiante, el contexto ideológico está servido, pues no se trata sino de una gran conciencia intelectual, socialista para más señas, que denuncia y prepara a las masas para alzarse contra la feroz tiranía, liberar esperanzas y mostrarse a pecho descubierto proclamando el grito de jrevolución o muerte!.

\section{Y Realidad y Maravilla se volvieron una}

Los contextos que se acaban de enumerar, recordemos, son los que permiten al novelista situar al hombre americano en el lugar que la Geografia y la Historia les ha colocado y, con ello, abordar de forma enteramente consciente la dimensión épica de que es portadora la actual novela latinoamericana. Hay que señalar, por otro lado, que todos estos contextos no forman sino los elementos de una naturaleza, la latinoamericana, que es insólita en tanto que es la que el habitante nacido alli observa día a día, pero también es aquella que para el euro- 
peo desconocedor de estas tierras tendria algo de fantástico o de inverosimil, como inconcebibles pudieran resultar los acontecimientos trágicamente reales que tenemos ocasión de conocer en El recurso del método:

Y es que, por la virginidad del paisaje, por la formación, por la ontologia, por la presencia fáustica del indio y del negro, por la revelación que constituyó su reciente descubrimiento, por los fecundos mestizajes que propició, América está muy lejos de haber agotado su caudal de mitologías. ¿Pero qué es la historia de América toda sino una crónica de lo real maravilloso ${ }^{57}$.

\section{- El pan de cada dia: el mito}

Por ello, encontramos a un personaje real descrito en su novela El reino de este mundo, llamado Mackandal, al que por la fe del pueblo, se le atribuía el poder de transformarse en diferentes animales, escapando, asi, de las autoridades francesas y, con ello, llegando a motivar el deseo de sublevación de los esclavos haitianos. Podemos ver también referencias similares en El recurso del método, recordadas por el propio dictador, como la de Moctezuma, que "fue derribado por el mito mesiánico-azteca de Un-Hombre-de-Tez-Clara-que-habría-devenir-del-Oriente"; el mito de Emiliano Zapata, "subiendo al cielo, después de muerto, en un caballo negro con aliento de fuego" o, también, en México, donde "tumbaron a nuestro amigo Porfirio Díaz con el mito de 'Sufragio efectivo, no reelección' y el despertar del Águila y la Serpiente, que bien domados estaban, para suerte del país, desde hacía bastante más de treinta años". "Y, ahora, (...), el Mito del Estudiante" ${ }^{58}$, ya referido anteriormente.

Pero esta conjunción dada del mito con la realidad no sólo está presente en el escritor cubano, también se encuentra en la gran novela del colombiano Gabriel García Márquez, Cien años de soledad (1967), la cual no podría comprenderse del todo sin los presupuestos carpenterianos de los que se está hablando. Efectivamente, en ella, "lo que hace de Aureliano Buendia un ser especial, insólito y mágico en tanto que es de hecho sobrehumano, capaz de hazañas prodigiosas que no pueden ocurrir, tal cual, en la realidad (...), no es su realidad intrínseca, sino la poderosa inventiva de García Márquez y su infinita capacidad de exagerar, que hacen de un ser real (...) un personaje insólito, irreal en la medida en que es realmágico" 59 .

\section{- Realidad que supera a la ficción}

Hay que señalar, no obstante, que en $E l$ recurso del método el verdadero contexto que atestigua la presencia de lo real maravilloso, si bien tiene que ver con la ambivalencia de los dos planos, se halla particularmente en la separación del acá y el allá establecida a todo lo largo de la novela. Cada vez que el Primer Magistrado consigue sofocar, aunque sea momentáneamente, una sublevación, cada vez que sale airoso de cada una de las rebeliones dirigidas por aquellos que buscan ocupar su mismo puesto, se traslada a su casa de París, es decir, a esa Europa que le atrae y donde puede gozar cómodamente de su poder. Pero, como apunta Rogelio Rodríguez Coronel: 
En primer lugar, la traslación, el viaje, no lo promueve el mito de un mundo mejor; son hechos concretos, de indole política, los que motivan el recorrido que lleva a cabo el Primer Magistrado entre París y América Latina.

En segundo lugar, esa referencia espacial es portadora de una disimilitud histórico-cultural (...) que acondiciona la presencia de lo real maravilloso, cuyo origen se reconoce unido al descubrimiento de las esencialidades de la realidad. Lo real maravilloso se inserta dentro de una perspectiva más coherente y sistémica de lo histórico-concreto. Es un elemento que condensa y revela un fenómeno cultural cuyo sustrato básico es socioeconómico ${ }^{60}$.

El mismo Alejo Carpentier aceptaría esta afirmación cuando explica que entorno a ese eje bipolar de los dos escenarios gira un "mundo de diplomáticos, extranjeros, negociantes, especuladores, paniaguados, militares, parientes y compadres, cuyos intereses políticos y económicos son servidos por la permanencia de una dictadura" 61 , y de entre los cuales podemos señalar la presencia familiar y próxima del sastre y del barbero del Primer Mandatario, la de sus dos más fieles amigos intelectuales, el Ilustre Académico y D’Annunzio, su no tan fiel secretario Peralta, el diplomático Cholo Mendoza, su dama de llaves y compañera ocasional, la Mayorala Elmira y, más directamente, su hija Ofelia.

Habría que recordar una cosa más y es que esta preocupación por parte del dictador de perpetuarse en el poder y, con ello, salvaguardar los intereses de clase de sus correligionarios, responde a una verdad histórica que pudiera parecer inverosímil pero que se constituye en una trágica realidad y es el hecho de que América Latina ha conocido desde 1824, al comenzar la era de su independencia, más de doscientos gobiernos dictatoriales ${ }^{62} \mathrm{y}$, esto, ciertamente, forma parte de lo real maravilloso, de lo que es intrínseco a esa realidad, de lo que no es objeto de interpretación. Es lo que, tomando las palabras de Carpentier, se encuentra "al estado bruto, latente, omnipresente en todo lo latinoamericano", donde "lo insólito es cotidiano" $"$.

\section{Lo barroco latinoamericano}

\section{- Espíritu barroco: constante universal para un arte particular}

Claro que esa omnipresencia de lo real maravilloso debe ser traducida, debe ser expresada de una peculiar manera y Alejo Carpentier piensa que el escritor debe realizar un esfuerzo introspectivo que le lleve a admitir el hecho de que el estilo y el lenguaje utilizados para mostrar otras realidades, no pueden funcionar cuando se trata de mostrar ésta. Porque ésta es distinta y el criollismo, el concepto que tiene el hombre americano de ser producto de muchas mezclas, le lleva a tomar "conciencia de ser otra cosa, de ser una cosa nueva, de ser una simbiosis"64. La fusión de razas, culturas y experiencias que se vienen a concentrar en el espíritu criollo obedece a poner en práctica un lenguaje distinto que se rige por leyes que el escritor latinoamericano debe conocer y asumir. Y, ¿por qué debe asumirlas?. Porque, como dice el novelista cubano, - haciendo también suyas las palabras de Eugenio d'Ors-, el barroco es una constante humana (no un estilo circunscrito a una época y a unos cánones) que surge espontánea cuando se produce un cambio, una nueva era en los tiempos de la Histo- 
ria, es decir, "cuando hay transformación, mutación, innovación"65. Y es que, comprueba, en la historia de América toda, desde mucho antes de que fuera descubierta, desde los antiguos libros, pinturas, esculturas y monumentos, encontramos esa suerte de pulsión, de desorden dentro del orden, de fusión de elementos, de cambios, de variaciones, de carnaval artístico que, sin sujetarse a moldes, contextos, límites o espacios, pareciera que está en movimiento. En América, ese espíritu, que rompe barreras, ha perdurado hasta nuestros días, pues no es otra cosa que un impulso que se dirige hacia delante, en sus formas y en su fondo y, en las novelas de no pocos autores, se asienta sobre una base historicista que conduce al escritor a establecer múltiples asociaciones entre el ayer y el hoy, el acá y el allá, entre experiencias, creencias y modos de ser lejanos en el tiempo pero constantes por cuanto que se hacen presentes en el aquí y ahora.

\section{- Nuestro nombre es América Latina}

Para poder llegar a ello, según Carpentier, surge una necesidad, que no es otra que la de "nombrar las cosas", esas cosas nuestras cuya denominación particular ha de ser incorporada a la cultura universal, lo que constituye una de las grandes tareas del escritor en pos del conocimiento de lo íntimo americano:

En La consagración de la primavera, por ejemplo, hay un paisaje en el cual describo el Caribe, el mar, la playa, los cocoteros; es decir, todo lo invisible o diferenciado que acompaña a la realidad, con palabras que estaban creadas para describir una playa de España, o los árboles de Castilla. Trataba de hacer pasar a través de las palabras del español la otra cosa que faltaba. Y lo mismo sucedía con lo demás, como por ejemplo el miedo, el amor, que no son los mismos en Francia que en Cuba, que en China ${ }^{66}$.

Es por ello por lo que en El recurso del método, Alejo Carpentier lleva a la realidad cotidiana un lenguaje propio y habitual, plagado de americanismos, como él mismo reconoce que quiso hacer Valle-Inclán (escritor barroco por excelencia para el cubano) en su Tirano Banderas, creando "un lenguaje formado por las distintas hablas del Continente", tomando las palabras de Luisa Campuzano, que ha estudiado con profundidad la utilización de los americanismos en la novela carpenteriana. Estos van desde el "empleo aislado" de determinadas categorías léxicas tales como "sustantivos" y "adjetivos" comunes en determinados países, que en otras ocasiones sustituye por los americanismos correspondientes ("plátano y banano"; "campesino y guajiro"; "pobre y pelado"), hasta "enumeraciones" (la de los platos servidos por la Mayorala Elmira, que ya se vio), pasando por la "amplificación barroca" de términos que "significan aproximadamente lo mismo" en diferentes lugares del Continente ("urbanización, reparto y parcelamiento"; "soga, reata, correia y cabuya") o la "inclusión de fragmentos", tales como la descripción de las raices recogidas por un agente consular norteamericano ${ }^{67}$.

Así, su idea de lo real maravilloso viene a complementarse con su concepto de lo barroco americano, cobrando sentido en tanto en cuanto se convierten en referente real y medio de conocimiento y de comunicación con el mundo. 


\title{
Conciencia histórica en Alejo Carpentier
}

Análisis de la realidad social

\section{- El Primer Magistrado: dictador de dictadores}

Partiendo de la propia idea de Alejo de que sus novelas "están siempre asentadas en una base histórica muy real" ${ }^{68}$ que, por otra parte y, como hemos visto hasta ahora, le sirve de presupuesto para indagar en la realidad latinoamericana, cabe decir que esa indagación le hace comprender que los tiempos de las diferentes edades pueden coexistir y establecer lazos de comunicación, identificarse, interrogarse o enfrentarse; que, de la misma manera que el pasado latinoamericano es pasado de luchas humanas y duros partos que trajeron nuevos tiempos, el presente, hijo legítimo de su propia historia, nos habla, con nuevas voces, nuevos contextos, nuevos dolores y esperanzas, de conflictos heredados, savias congénitas, sueños encontrados que volverán a ser absorbidos, succionados, alimentados en la fibra sensible de nuevas generaciones en el cometido de alcanzar su máxima perfección.

En nuestra novela, ya lo sabemos, El Primer Magistrado es el primero, efectivamente, de los tiranos que asfixiaron a un pueblo, y también es el segundo, y el tercero y el siguiente y el último de una larga serie que Alejo Carpentier y su América entera pudieron conocer antes de que él muriera un 24 de abril de 1980. Pero, ¿qué seguridad tenemos de que pueda ser el último si conocemos bien los resortes que generan este tipo de gobiernos?. Ante toda posible duda, nos dice Ariel Dorfman:

\begin{abstract}
...Al ciclo reiterativo de la opresión se opone la espiral dura de una acción liberadora que busca emerger. A la fragilidad del tirano de la periferia se opone la resistencia de esa periferia a ser administrada desde fuera. Para unir cronología (el tiempo objetivo y único) y estructura (el tiempo esencial y sistemático) no hay otro camino que romper con la organización institucional y económica vigente ${ }^{69}$.
\end{abstract}

Por ello, no podemos alargar las horas de este Primer Magistrado, entrado ya en decadencia en las últimas páginas de la novela, no podemos permitirle el goce de "la dilatación, que al tiempo impone un inmediato peligro de muerte", si no es para que en su agonia final, el goteo de un grifo le susurre obsesivamente "never-more, never-more, never-more" 70 .

Pero volvamos atrás en el tiempo de la acción y veamos a este personaje, a este pícaro tremebundo, que consigue perdurar en el poder cerca de veinte años, olvidándose de sus orígenes y traicionando a su antecesor literario, el pícaro español, llegando "en ascendente espiral de juego de la oca, del Surgidero a la Capital" 71 , pasando de su antigua "casona de tres cuerpos y dos tejados"72, a su ahora Palacio Presidencial, pasando de su plato único familiar a los manjares y exquisiteces, -por no decir excesos de coñac y ginebra-, de los banquetes diarios; sustituyendo, en fin, su humilde oficio de periodista provinciano por el de opresor del proletario en toda regla.

\section{- El tirano hispanoamericano defrauda la moral francesa. El discurso carpenteriano del recurso}

Una vez apoltronado en su trono del país innominado, cada vez que consigue escamotear conflictos mal avenidos, -pues "había que ser duro, implacable: lo exigian las Fuerzas Impla- 
cables, inmisericordes, que eran la obscura y todopoderosa razón de ser de su mundo en gestación, aún problemático en cuanto a formas, voliciones, impulsos y limites"73-, se traslada a París, "santo lugar del buen gusto, del sentido de la medida, del orden, de la proporción"74. Irónicamente establece Alejo Carpentier una oposición de dos mundos en que se mueve el personaje protagonista, el de América y el de Europa; oposición que, por otro lado, se justifica a partir del mismo titulo de la novela:

El recurso del método es un simple juego de palabras sobre el Discurso del método de Descartes. Los capitulos aparecen enlazados por citas del gran filósofo francés que vienen a justificar arbitrariamente los actos de las personas totalmente anticartesianas, porque no hay nada más anticartesiano que el continente latinoamericano, su mentalidad y su trayectoria histórica. Por lo tanto, se trata de un simple juego de palabras. El dictador personaje central de mi novela, recurre siempre a un método que consiste en no tener ninguno ${ }^{75}$.

Precisamente por ello, esa Francia no va a aceptar el modo de actuar del dictador; su racionalismo cartesiano no va a poder transigir con su manera de mantener el orden. Pero la burla carpenteriana va mucho más allá puesto que Europa, por entonces, se encuentra en guerra, una guerra cruenta de la que por otra parte se está alimentando un fascismo incipiente en Italia, así como también el Primer Magistrado y su séquito.

\section{- Una nueva razón contra el viejo método}

Por si fuera poco, la ironía llegará a su máximo grado porque tanto el cartesianismo europeo como la feroz tiranía empiezan a ser sustituidos, ya desde la revolución bolchevique, por un nuevo desorden organizado, una nueva razón:

...la estampa del Estudiante era invocada en los corrillos de cuarterías, en las veladas de conventillos, en las coplas que a media voz nacian de trastiendas aldeanas (...) como una suerte de reformador combatiente, defensor de pobres, enemigo de ricos, azote de corrompidos, recuperador de una nacionalidad alienada por el capitalismo, con antecesores en varios caudillos populares de nuestras guerras de independencia que, por sus actos generosos y justicieros, seguian viviendo en la memoria de las gentes ${ }^{76}$.

Se trataba de algo muy serio para la seguridad del Estado, pues parecía que aquella fuerza arrolladora que asomaba sin timideces venía a generar el caos (proclamando la primera Huelga General) y, acaso, lo que sería peor para el gobierno, una aplastante victoria. Así, el periódico Liberación publicaba:

La siempre severa antología de conceptos marxistas, puestos en recuadro: La humanidad no se plantea nunca sino problemas que puede resolver porque, si bien se mira, se verá siempre que el problema sólo surge allí donde ya existen las condiciones materiales para resolverlo (Contribución a la crítica de la economia política) ${ }^{77}$.

Solución posible contra "el recurso del método". El hombre del siglo XXI

Esta es la nueva, la verdadera fuerza revolucionaria que Carpentier trata de contrastar con otros tipos de resistencia contra el poder pero por el poder, como la que se lleva a cabo por el General Ataúlfo Galván, que termina muriendo fusilado; o la sublevación del Coronel 
Walter Hoffman, mestizo de origen alemán, que muere en un pantano de la selva; y también la que perpetra, con su partido "Alfa-Omega", el profesor Luis Leoncio Martinez que, apoyado por los norteamericanos, consigue alcanzar el poder e instaurar, de nuevo, un orden represivo. Recursos estos para un mismo método, resistencias que no buscan mejorar el ser del hombre sino, antes bien, perpetuar en el tiempo las tareas de Sísifo.

En cambio, es y será el Estudiante el que encienda una llama de esperanza en el hombre, ya que no pretende conquistar aquello contra lo que se subleva, sino conquistar un nuevo orden social, abanderado por una libertad que puede ser posible en el reino de este mundo. Así, en El recurso del método esa posibilidad queda planteada; esa esperanza en el porvenir no se frustra por el hecho de que el enemigo consiga la victoria, ya que ésta no se presenta como definitiva. La parcela de tiempo que nos toca vivir no ha de sernos engañosa, no ha de clausurar la ilusión; el sueño de la revolución no es individual, es también el sueño de los que entregaron su vida por verlo hecho realidad y de los que vendrán al mundo para luchar y morir por él. La victoria depende de que ese anhelo colectivo, transmitido a través de los tiempos, no cese. En la novela entra, con paso firme, a cobrar protagonismo la solución revolucionaria, fundadora en el pueblo de esa conciencia. Y ésta es la teoría carpenteriana que retoma de la Revolución cubana, para terminar llevándola a la práctica, como dice Víctor Bravo "en los insobornables de Sierra Maestra que cierran La consagración de la primavera ${ }^{78}$, es decir, los hombres del siglo XXI que los nuevos escritores deben crear, aunque, siguiendo con las propias palabras de Ernesto Che Guevara en su ensayo de 1965, El socialismo y el hombre en Cuba:

...todavía es una aspiración subjetiva y no sistematizada. Precisamente este es uno de los puntos fundamentales de nuestro estudio y de nuestro trabajo y en la medida en que logremos éxitos completos sobre una base teórica o viceversa, extraigamos conclusiones teóricas de carácter amplio sobre la base de nuestra investigación concreta, habremos hecho un aporte valioso al marxismo-leninismo, a la causa de la humanidad ${ }^{79}$.

\section{Espacios y planos del tiempo}

El espacio en el que se localiza el hacer y decir de los personajes, sobre todo del protagonista, es elemento que confiere movilidad a la narración, pero también un sistema que sirve para contraponer ideas o realidades. Así, la repetición de los adverbios acá y allá por parte del Primer Magistrado a todo lo largo de la novela es sintomática de la apreciación de dos mundos diferentes, el de Europa (y, a su vez, Estados Unidos) y el de América Latina. Dos espacios que difieren social (desarrollo y subdesarrollo) y culturalmente (educación y analfabetismo, formas de vida y costumbres), pero que encuentran un punto de intersección en lo que se refiere a la historia politica y a los intereses que la generan (descubrimiento, ocupa-ción, guerras, independencia, dependencias). El sucesivo ir y venir de América a París y de París a América por parte del dictador, permite establecer los contrastes oportunos pero, sobre todo, dirigir la mirada hacia la peculiaridad latinoamericana, objeto de estudio del novelista. 
En cuanto al tiempo, ya nos referimos al concepto que de él tiene el escritor cubano para decir que viene a constituirse en verdadero elemento estructural de sus más grandes narraciones y, en concreto, de El recurso del método. El tiempo se encuentra en lógica trabazón con la Historia porque ésta está formada no sólo por los diferentes instantes de cada una de las vidas de los hombres, sino también por las diferentes épocas en que se suceden, una tras otra, las generaciones. Pero hay algo más, y es que la visión que nuestro escritor tiene del tiempo es enteramente dialéctica por cuanto que el pasado, el presente y el futuro de la humanidad pueden darse la mano en un mismo momento histórico. Ya puede verse en su novela Los pasos perdidos, donde el tiempo representa un papel fundamental, vital para el narrador protagonista, en el sentido de que se establece un diálogo perturbador entre su yo circunstancial y su yo profundo, lo que le lleva a realizar un viaje en el espacio y en el tiempo desde Nueva York hasta todo lo largo y profundo del Orinoco.

En El recurso del método podemos encontrar el tratamiento del tiempo que, tomado desde diferentes enfoques o perspectivas que se entrecruzan, confiere al texto una verdadera consistencia argumental y estructural.

Tiempo histórico de la novela y plano del discurso narrativo

El tiempo histórico de la novela es el tiempo real en el que se circunscribe la acción de los sucesos narrados y que, como quedó dicho al principio, va desde poco antes de iniciarse la Primera Guerra Mundial, hacia 1913 (con el dictador en el poder), en gran parte favorecedora del capitalismo en América Latina (movilidad social y económica, crecimiento de las ciudades), pasando por la Revolución rusa de 1917 (de la que es deudora la penetración del comunismo por parte del Estudiante), y que acabó con el régimen zarista; hasta, más tarde, la ascensión del fascismo italiano y el inicio del gobierno de Benito Mussolini en 1924; sin olvidar, claro está, la presencia de los Estados Unidos en todo momento (sometimiento económico, político y cultural del gobierno que rige la vida del país).

La acción, los acontecimientos presentados que encierra tal contexto histórico vienen a constituirse en un segundo plano que, visto por María Rosa Uría Santos ${ }^{80}$, es aquel donde el inicial desarrollo y engrosamiento de las actividades del Primer Magistrado y su progresiva decadencia y regreso definitivo a París, se corresponde con una sucesión lineal e histórica de los hechos para concluir con una suspensión temporal en la que el ex-dictador empieza a perder memoria, desorganizándose todo en su cabeza:

Y el Cholo empezó a alarmarse con los desvaríos del Patriarca, un día 5 de mayo, en que despertó con la idea fija (...) de mandar un enorme ramo de flores a los Inválidos, por ser el aniversario de la muerte de Napoleón en Santa Elena ${ }^{81}$.

\section{El hombre frente al tiempo}

En una ocasión decía Alejo Carpentier que El recurso del método muestra "el tiempo de ayer en hoy, es decir, un ayer significado presente en un hoy significante" 82 . Imagen que refleja esta idea es la del reloj, aludida en tres momentos de la novela, uno al principio (I, 1), otro hacia la mitad (III, 8) y otro, casi llegando al final (VII, 21); y, en todos, haciendo empleo de idénticas palabras: 
Este despertador, será un portento de relojería suiza, pero sus agujas son tan finas que apenas si se ven ${ }^{83}$.

Esta armonia espacial, temporal y lingüistica nos viene a hablar de la recurrencia temporal en que se suceden los hechos, es decir:

Con este evento Carpentier no sólo nos mantiene en el mismo lugar, con las mismas vivencias, en la misma hora, en la misma estación, sino también en el mismo dia en que empezaron a desenvolverse los acontecimientos novelescos ${ }^{84}$.

Sin embargo, frente al "círculo mágico" en el que se encierran los pensamientos del dictador, frente a su papel en la Historia,

La Historia, que era la suya puesto que en ella desempeñaba un papel, era historia que se repetia, se mordia la cola, se tragaba a si misma, se inmovilizaba cada vez (...). El cuchillo clásico al que cambian el mango cuando está gastado, y cambian la hoja cuando a su vez se gasta, resultando que, al cabo de los años, el cuchillo es el mismo ${ }^{85}$;

Frente a esa concepción cíclica y cerrada del devenir de los tiempos, encontramos la visión aperturista de una historia que aún está por ver en el Estudiante. En el diálogo que entablan cara a cara leemos:

- “Asi que sigue la guerra? - "Seguirá, conmigo...o sin mi”. “¿Persistes en tus utopías, tus socialismos, que han fracasado en todas partes?" - "Es asunto mio...y de muchos más". - "La Revolución Mexicana fue un fracaso". - "Por eso nos enseñó tanto". - "Lo de Rusia ha fracasado ya". - "Todavía no está demostrado" 86

Por tanto, resulta imposible compartir la idea de que en El recurso del método el autor ofrece una visión pesimista de la Historia y de la realidad, como cierta crítica ha querido entender. No se puede concebir la afirmación hecha por parte de Esther P. Mocega-González de que, -aunque sabemos que al final de la novela se produce una nueva restitución de un orden que no dista en nada del que sustenta el dictador-, "el escritor no ve la posibilidad de que el hombre pueda romper este círculo mágico espacio-temporal en el que se le ha aprisionado en la superficie de la tierra" 87 . Esta imposibilidad no se ve por ningún lado.

Actitud del protagonista respecto al tiempo

El Primer Magistrado es un tirano ilustrado, afrancesado, pero su cultura no solamente es de préstamo francés, sino que forma parte del pasado. El culto que ejerce a la música, la literatura o la pintura, se enmarca dentro de las corrientes racionalistas que estuvieron en boga en Europa, sobre todo en la Francia cartesiana. Rechaza el nuevo panorama cultural y artístico que empieza a abrirse camino; no lo entiende, no lo acepta. Los cuadros de vanguardia que Ofelia ha colocado en las habitaciones de la estancia de Paris, le parecen "cuadros locos, absurdos, herméticos, sin evocaciones históricas o legendarias, sin asunto, sin mensaje", cuadros, en fin, donde "hacía falta un dominio del dibujo, un manejo de los escorzos" 88 . Pero muestra máxima de su rechazo del presente es la que se refiere a la lectura, incomprensible para él, de una nueva literatura que habla de "anarquismos, socialismos, comunismos, inter- 
nacionales obreras, revoluciones..." ${ }^{89}$, confundiendo, por otra parte, los términos. Libros rojos que habrían de ser rastreados, incautados, introducidos en el incinerador de basura por la mano inquisidora de la cultura oficial. Como inquisidora le parecerá también la mirada de una momia hallada en campo de batalla, regalada al Museo del Trocadero de Paris, y con la que el ex-Mandatario se reencontraría, casi al final de sus días, como observándole "desde sus incontables siglos" $"$.

\section{El recurso del método como novela de dualismos y contrastes}

La concepción dialéctica del mundo y de la Historia con la que Alejo Carpentier toma posición a la hora de escribir sus novelas, le da entera libertad no sólo para presentar los asuntos narrados en función de una lucha de contrarios, sino también para tratar esos asuntos desde diferentes enfoques -los que se filtran a través de las voces y actitudes de cada uno de los personajes-, estilos o recursos:

\section{Realidades opuestas}

En El recurso del método se puede advertir una primera oposición como es la que se establece entre una realidad cartesiana y una realidad anticartesiana. Francia es el país cartesiano por excelencia, donde la lógica y la razón, el savoir-faire controla los instintos. América, en cambio, se nos presenta como tierra de brutales fuerzas telúricas, como tierra embravecida por una naturaleza que el hombre, parte integrante de ella, no ha podido apaciguar ni domesticar. Su severidad irreductible se corresponde con la despiadada crueldad del tirano. Por otro lado, si su actitud provoca el rechazo calmado y pacífico de los que fueran sus colegas de París, engendrará la discordia, la rebelión y el caos en tierras americanas. Pero no hay que olvidar, sin embargo, que el contraste entre el acá y el allá, la contraposición entre dos formas de hacer y de ser, esto es, la de Europa en su conjunto y la de Latinoamérica en particular, si se mantiene desde este punto de vista, el del Primer Magistrado (como arquetipo representante de una determinada colectividad), queda anulada ante los ojos del espectador que es Alejo Carpentier, por la razón de que es la violencia y sólo ella el recurso de ambos métodos de actuación.

Otra de las oposiciones, a la que anteriormente se ha aludido, viene dada por dos conceptos ideológicos enteramente diferentes: de un lado, el que sustenta la idea de cambio sin la intervención del pueblo; de otro, el que persigue la ruptura del sistema por y con el pueblo. Tal contraste queda de forma suficientemente marcada en la novela cuando se alude al cuartelazo y a la revolución, es decir, de lo que se trata es de diferenciar, de un lado, el simple motín militar que llevan a cabo el General Ataúlfo Galván, el Coronel Walter Hoffman o el profesor Luis Leoncio Martínez con el objetivo de usurpar el poder del tirano para, consiguientemente, apropiarse de él y emplear con iguales o diferentes métodos los mismos recursos; y de otro, la auténtica rebelión que, en nombre de la revolución, pretende instaurar un nuevo gobierno, el del pueblo.

Por otra parte, es necesario subrayar el contraste significativo que se plantea entorno al progresivo desmoronamiento del poder europeo y la cada vez más imparable influencia del imperialismo norteamericano en la vida de Latinoamérica. El Arco de Triunfo, símbolo de la 
Francia imperial, vendrá a ser demolido por los cañones yanquis en nombre de una falsa democracia "que ellos invocan cada vez que quieren cambiar algo en América Latina" Tiranía de tiranías, la de Estados Unidos que, no conformándose con el control político de los pueblos del Sur, pretende adueñarse también de sus almas. Y este nuevo imperialismo, más corrosivo que el europeo, habrá de vérselas con una fuerza contumaz, antiimperialista, "porque los gringos tienen miedo al Estudiante y, más que nada, a las ideas que representa" 92 .

\section{Actitudes y personalidades}

Cabe destacar, por otra parte, la oposición de caracteres entre los diferentes personajes, sobre todo, los de aquellos que Carpentier ha procurado definir con más precisión. Por ejemplo, las características aludidas en la novela a la personalidad del Primer Magistrado dibujan a un ser ambivalente según el momento y el lugar en que se encuentre. Merece la pena leer lo que nos dice Maria Rosa Uría Santos sobre ello:

La dualidad del personaje, su continuo fluctuar entre un actuar natural, espontáneo, reflejo de su ser auténtico, y la máscara tras la que se oculta en su actuación pública, se manifiesta en la alternancia entre un lenguaje refinado, cargado de referencias cultas, y un lenguaje soez, de una rebuscada vulgaridad que aflora en sus expresiones iracundas: en la continencia y moderación de su conducta pública y los varios excesos de su proceder privado (bebida, sexo); en sus gustos exquisitos y sus hábitos groseros. A su vez, este dualismo se proyecta en (...) la vida artificiosa regida por preceptos lógicos y razonables y la vida instintiva, pasional, dominada por fuerzas subterráneas y oscuras...93

Pero este dictador, a su vez, se opone radicalmente al Estudiante. Si aquél aparece como un ser corrupto, mantenedor de un sistema totalitario que parece inamovible, éste se muestra como su antagonista más evidente: hombre incorruptible, imposible de comprar, fiel a su credo socialista, hermano del pueblo, combatiente, revolucionario, reformador, optimista. Es en el diálogo que mantienen frente a frente donde se resume el ser histórico de cada uno:

Y se contemplaban ambos, el Amo, el Investido, el Inamovible, y el Débil, el Soterrado, el Utopista, por sobre el foso de dos generaciones, viéndose las carnes por primera vez ${ }^{94}$.

Se puede advertir igualmente desarrollos divergentes entre el Mandatario y su hija Ofelia, en la medida en que el padre termina hundiéndose en el olvido y la soledad de su destierro y, ella, joven heredera de una sociedad senil, la europea, intenta prolongar los beneficios y encumbramientos que ésta le reporta en los nuevos tiempos que corren.

Ciertamente, Ofelia, mujer de "cutis mate de india adelantada" 95 no representa más que a la juventud de una vieja sociedad, superficial y arrastrada por las corrientes en boga para su simple disfrute y deleite, en contraste, por un lado, con los nuevos jóvenes, como el Estudiante, y la radical transformación social a la que aspiran; y, por otro, con la negra Elmira, que no puede acomodarse a los gustos y refinamientos franceses y prefiere vivir al estilo de allá. Ella, a su vez, será cómplice de los excesos y actos corruptos de su amo, como el Secretario Peralta, pero mientras éste termina traicionando al dictador destronado para acogerse a la protección del nuevo gobernador del país, aquella permanecerá fiel hasta el final. 


\section{El recurso del método: tragicomedia en siete capitulos}

No se puede concluir esta exposición sin señalar que el humor, la ironía, el sarcasmo, la parodia y hasta el esperpento, impregnan el conjunto de la narración, como si de un espectáculo circense se tratara. Ya se pueden leer algunas frases absurdas y cómicas sobre estrategias militares, extraídas de libros clásicos que el Coronel Hoffman guardaba en sus maletas, como aquella de "La victoria resulta del hecho de ganar una batalla (Scharnhorst)" "96; o asistir a los pormenores de la construcción de un capitolio nacional que "con uso interior de maderas nacionales y mármoles nacionales" habria de ser ni más ni menos que "una réplica del Capitolio de Washington" 97 , bajo cuya cúpula tendría que alzarse una gigantesca estatua de la República, traída a pedazos de dimensiones incalculables (por maquinaria pesada, claro), como podría ser una cabeza, de rostro desconocido, nunca visto por el público, a causa de la desproporción descomunal, erigida en las alturas, de un cuerpo que la ocultaba ${ }^{98} \mathrm{O}$, siguiendo otro tramo de la lectura, no podemos evitar la carcajada cuando, en la requisa masiva de los libros rojos, uno de los libreros, sugiere, -ante el avasallamiento al que se ve sometido por el considerado impúdico color-, que se lleven también La caperucita roja ${ }^{99}$. $\mathrm{O}$, en fin, ahí están a todo lo largo de la novela, las comparaciones irónicas entre una Francia y una América Latina, vistas a través del deformado cristalino de un dictador que persiste en deleitar su mirada en un Arco de Triunfo cada vez más adintelado y menos triunfal.

Alejo Carpentier, quiso descubrir ante el mundo la sinrazón de las personas que poblaron su querida tierra; personas que, sin querer avanzar en el arduo y sacrificado camino de ser hombres, posaban sus pies siempre sobre la huella de sus antepasados, dejando, en ese camino, un inmenso foso, cavado concienzudamente, que se agigantaba y se consolidaba al paso de los años, y al que iba a parar, sin conmiseración alguna, el trabajo labrado y amasado de muchas vidas que ya se fueron. También nos enseña que otros hombres han venido al reino de este mundo a lanzarse a ese pozo, profundo y oscuro, para rescatar esas almas que se llevaron consigo sus ilusiones y esperanzas, y devolverles la luz con la que un día iluminaron la tierra de su entraña. La humillación ha llegado a su límite y, los nuevos hombres, más fuertes hoy que nunca, ya no pueden permitirse la burla macabra de aquél que arrebató el tiempo y la libertad de su ser auténtico. Ha llegado la hora de reírse de él, ha llegado la hora de cuestionar su poder, su fuerza, su resistencia secular, su omnipotencia; los argumentos sobran, las conciencias despiertas cada vez son más. Por ello, de alguna manera, Alejo Carpentier nos está diciendo que el humor no es sino la constatación de lo que está ocurriendo, la prueba de que se sabe, él sabe, lo que está ocurriendo y lo que tiene que ocurrir. Así, la sutileza o agudeza con las que nos inyecta toda la información, hace que ésta nos llegue de manera que conmueva, altere, remueva formidablemente al lector, pues más y más diáfana y más y más próxima se le vuelve la gran tragedia a la que asiste.

\section{Notas}

1 Alejo Carpentier, "Razón de ser", en Ensayos, La Habana, Letras Cubanas, 1984, p. 89.

2 Ibid., p. 89.

3 Ibid., p. 106.

4 Alejo Carpentier, en "La guerra del 14 sigue hasta hoy", Entrevistas, La Habana, Letras Cubanas, 1985, p. 199. 
Ibid., p. 200.

6 Alejo Carpentier, en Alejo Carpentier, Premio "Miguel de Cervantes" 1977 (Paco Tovar, "Ideas y sonidos de Alejo Carpentier"), Barcelona, Anthropos, 1988, p. 65.

7 Alejo Carpentier, en Donoan, "La América de Alejo Carpentier como lo verdaderamente real maravilloso", ibid., p. 23.

8 Alejo Carpentier, en "Carpentier o el oficio de revelar", Entrevistas, p. 313.

9 Ibid., p. 313.

$10 \quad$ Ibid., pp. 313-314.

11. Alejo Carpentier, El recurso del método, México, Siglo XXI, 1974, p. 11.

12 Alejo Carpentier, en "La guerra del 14 sigue hasta hoy", op. cit., p. 204.

13 Julio Rodriguez Puértolas, "Significación de Alejo Carpentier", en Alejo Carpentier, Premio "Miguel de Cervantes" 1977, p. 83

14 Rita Gnutzmann, "Alejo Carpentier: El recurso del Método", en Anales de Literatura Hispanoamericana, no 4 , Madrid, 1975, p. 324.

15 Victor Bravo, Magias y maravillas en el continente literario, Caracas, Letras Universitarias, 1995, p. 153.

16 Alejo Carpentier, en "Carpentier, el hombre y la historia inimaginable", Entrevistas, p. 295.

17 Alejo Carpentier, en "El recurso del método”, Ramón Chao, Palabras en el tiempo de Alejo Carpentier, Barcelona, 1984, p. 82.

18 José Alcántara Almánzar, “ La dictadura y el dictador latinoamericanos en El recurso del método de Alejo Carpentier", en El dictador en la novela latinoamericana (ponencias de un seminario realizado los dias 2,3 y 4 de abril de octubre, 1980), Sto. Domingo, Voluntariado de las Clases Reales, 1980. Alejo Carpentier, El recurso del método, p. 33. Ibid., p.147. Ibid., p. 147.

José Alcántara Almánzar, op. cit., pp. 33-34. Alejo Carpentier, El recurso del método, p. 126. Ibid., pp. 149-150

Ibid., p. 181.

Ibid., p. 31.

José Alcántara Almánzar, op. cit., p. 34.

Alejo Carpentier, El recurso del método, p. 276

Alexis Márquez Rodriguez, Ocho veces Alejo Carpentier, Caracas, Grijalbo, 1991, p. 131.

Alejo Carpentier, "La novela latinoamericana en vísperas de un nuevo siglo y otros ensayos", Ensayos, p. 228.

Alejo Carpentier, en "El pícaro latinoamericano: general de cuartelazos, presidente de elecciones amañadas y, las más de las veces, dictador", Entrevistas, p. 205.

Ibid., p. 205.

Alejo Carpentier, "La novela latinoamericana en visperas de un nuevo siglo", op. cit., p. 229.

Ibid., p. 229.

Alejo Carpentier, en "Alejo Carpentier: una literatura inmensa", Entrevistas, p. 222.

Alejo Carpentier, "La novela latinoamericana en vísperas de un nuevo siglo", op. cit., p. 229.

Alejo Carpentier, El recurso del método, p. 121

Ibid., p. 84.

Alejo Carpentier, en "Alejo Carpentier: el recurso a Descartes", Entrevistas, p. 209.

Alejo Carpentier, "La novela latinoamericana en visperas de un nuevo siglo", op. cit., p. 181.

Alejo Carpentier, en "Hemos pasado del costumbrismo a la épica Latinoamericana", Entrevistas, p. 112.

Alejo Carpentier, El siglo de las luces, Barcelona, Planeta, 1990, p. 357.

Dario Villanueva y José Maria Viña Liste, Trayectoria de la novela hispanoamericana. Del "realismo mágico" a los años 80, Madrid, Austral, 1991, p. 108.

44 Ariel Dorfman, “ Entre Proust y la momia americana: siete notas y un epilogo sobre El recurso del método", en De elefantes, literatura y miedo: ensayos sobre la comunicación americana, La Habana, Casa de las Américas, 1986, pp. $84-85$.

Alejo Carpentier, en “ Hemos pasado del costumbrismo a la épica latinoamericana", op. cit., pp. 112-113. 
Alejo Carpentier, El recurso del método, p. 246.

Ibid., p. 45.

Ibid., p. 60.

Ibid., p. 44.

Ibid., p. 312

Ibid., pp. 28-29

Ibid., p. 98.

Ibid., p. 11.

Ibid., p. 314.

Ariel Dorfman., op. cit., p. 85.

Alejo Capentier, El recurso del método, p. 232.

Alejo Carpentier, “Tientos y diferencias”, Ensayos, p. 79.

Alejo Carpentier, El recurso del método, pp. 232-233.

Alexis Márquez Rodriguez, op. cit., p. 79.

Rogelio Rodriguez Coronel, en Letras. Cultura en Cuba (7), La Habana, Pueblo y Educación, pp. 175-176.

Alejo Carpentier, en "Alejo Carpentier: una literatura inmensa", op. cit., p. 224.

Alejo Carpentier, en "El dictador y su pintor", Entrevistas, p. 464.

Alejo Carpentier, en "Razón de ser", op. cit., p. 122.

Ibid., p. 119.

Ibid, p. 116.

Alejo Carpentier, en "La vida es la materia misma de la escritura", Entrevistas, pp. 486-487.

Luisa Campuzano, "Apuntes para un estudio de la función de los americanismos en El recurso del método", en Letras. Cultura en Cuba (5), pp. 153-154.

Alejo Carpentier, en "Jamás me ha defraudado la Revolución cubana", Entrevistas, p. 478.

Ariel Dorfman, op .cit. p. 86.

Alejo Carpentier, El recurso del método, pp. 284285.

Ibid., p. 68.

Ibid., p. 67.

Ibid., p. 45.

Ibid., p. 25.

Alejo Carpentier, en "El picaro latinoamericano: general de cuartelazos, presidente de elecciones amañadas y, las más de las veces, dictador", op. cit., p. 207.

Alejo Carpentier, El recurso del método, p. 231.

Ibid., p. 230.

Victor Bravo, op. cit., p. 159.

En José Antonio Portuondo, "Itinerario estético de la Revolución cubana", Letras. Cultura en Cuba, 7, p. 61.

Maria Rosa Uría Santos, "El recurso del método: una exploración de la realidad hispanoamericana", Anales de Literatura Hispanoamericana, 5, Madrid, 1976, p. 390.

Alejo Carpentier, El recurso del método, p. 332.

Alejo Carpentier, en "Razón de ser", op. cit., p. 142.

Alejo Carpentier, El recurso del método, pp. 11, 132 y 337.

Esther P. Mocega-González, Alejo Carpentier: estudios sobre su narrativa, Madrid, Nova Scholar, 1980 , p. 85.

Alejo Carpentier, El recurso del método, pp 128-129

Ibid., p. 241.

Esther P. Mocega González, op. cit., p. 85.

Alejo Carpentier, El recurso del método, p. 300.

Ibid., p. 179.

Ibid., p. 334.

Ibid., p. 251.

Ibid., p. 251.

Maria Rosa Uria Santos, op. cit., p. 389.

Alejo Carpentier, El recurso del método, p. 234. 
Ibid., p. 27.

96 Ibid., p. 75.

97 Ibid., p. 154.

98 Ibid., p. 158.

99 Ibid., p. 181.

\section{REKURZ V METODI ALEJA CARPENTIERA - KRONIKA NAPOVEDANEGA UPORA}

Avtorica v članku obravnava dialektični odnos do sveta in zgodovine v sodobnem latinskoameriškem romanu, še posebej v delu "El recurso del método" kubanskega pisatelja Aleja Carpentiera. Naracija je resničen prikaz diktatorja, ki se v želji po nesmrtni slavi (vzor so mu véliki francoski vladarji iz preteklosti) v domačem, latinskoameriškem okolju izpostavlja nesmiselnim ali ironično-sarkastičnim primerjavam. 